\title{
Biotin-response Organicaciduria
}

\author{
MULTIPLE CARBOXYLASE DEFECTS AND COMPLEMENTATION STUDIES \\ WITH PROPIONICACIDEMIA IN CULTURED FIBROBLASTS
}

\author{
M. Saunders, L. Sweetman, B. Robinson, K. Roth, R. Cohn, and R. A. Gravel, \\ The Research Institute, Hospital for Sick Children, Toronto, Ontario M5G \\ 1X8, Canada; Department of Pediatrics, University of California, San Diego, \\ La Jolla, California 92093; Division of Biochemical Development, Children's \\ Hospital, Philadelphia, Pennsylvania 19104
}

A B S T RA C T Fibroblast cultures from two individuals with biotin-responsive organicacidemia were found to have a pleiotropic deficiency of propionylCoA carboxylase, $\beta$-methylcrotonyl-CoA carboxylase, and pyruvate carboxylase activities after growth in biotin limited culture medium, conditions which do not affect the carboxylase activities of normal cells. All three enzyme activities were restored to normal levels after transferring the mutant strains to biotin-rich medium. Both patients excreted abnormal levels of an array of metabolic intermediates, including $\beta$-methylcrotonate, $\beta$-hydroxyisovalerate, $\beta$-hydroxypropionate, and lactate, which reflect metabolic blocks at all three carboxylase sites.

14 mutants deficient in only propionyl-CoA carboxylase activity from patients with propionicacidemia and the two biotin-responsive strains were examined for complementation with seven previously mapped $p c c$ mutants. No new pcc complementation groups were identified. Nine of the mutants were mapped to group $p c c A$. The remaining 12 mutants mapped to $p c c B C$ or its $B$ or $C$ subgroups, confirming the complex nature of this group. The biotin-responsive mutants failed to complement each other but did complement mutants from all the pcc groups. Thus biotin-responsive organicacidemia is defined by a new complementation group, bio. The results obtained in this study suggest that the bio mutants have a defect of either biotin transport or a common holocarboxylase synthetase required

Ms. Saunders is the recipient of a Centennial Sciences Fellowship from The National Council of Canada. Dr. Gravel is a Scholar of The Medical Research Council of Canada. Address reprint requests to Dr. Gravel, Research Institute, Hospital for Sick Children, Toronto, Canada M5G 1X8.

Received for publication 9 April 1979 and in revised form 13 August 1979. for the biotin activation of all three mitochondrial carboxylases.

\section{INTRODUCTION}

Four major carboxylases that require biotin for activity are known to function in human cells. These are $(a)$ propionyl-CoA carboxylase (PCC, EC 6.4.1.3), ${ }^{1}$ involved in the catabolism of isoleucine, valine, and fatty acids with odd-numbered chain lengths, $(b) \beta$ methylcrotonyl-CoA carboxylase (MCC, EC 6.4.1.4), important in the degradation of leucine, $(c)$ pyruvate carboxylase (PC, EC 6.4.1.1), a gluconeogenic enzyme, and $(d)$ acetyl-CoA carboxylase (EC 6.4.1.2) which initiates fatty acid synthesis. Various genetic disorders have been described in which there is a deficiency of one or more of these enzyme activities.

Deficiency of PCC activity results in propionicacidemia, a disorder in which extensive clinical heterogeneity has been observed $(1,2)$. In its most debilitating form, it is one of the causes of the ketotic hyperglycinemia syndrome (1), a condition that is usually lethal in the neonatal period. Other individuals may be less severely affected (3-5) and one case has been reported in which expression of the enzyme deficiency was virtually benign (6).

To examine the extent and basis of the genetic heterogeneity observed in patients with a PCC defect, we undertook a study of complementation between fibroblasts strains from such patients (7). Two major complementation groups, $p c c A$ and $p c c B C$, were revealed among seven mutant strains. These groups may cor-

\footnotetext{
${ }^{1}$ Abbreviations used in this paper: $\alpha$-MEM, alpha minimal essential medium; FCS, fetal calf serum; MCC, $\beta$-methylcrotonyl-CoA carboxylase; PCC, propionyl-CoA carboxylase; PC, pyruvate carboxylase.
} 
respond to separate genes involved in the expression of PCC, or they may have resulted from intragenic events.

Some patients have been described with an organic aciduria in whom correction of the biochemical abnormality has been attempted with biotin therapy (811). One such biotin-responsive patients, originally described by Gompertz and his colleagues (8), presented with $\beta$-methylcrotonylglycinuria and was shown to have a combined deficiency of two carboxylase activities, PCC and MCC $(12,13)$. Weyler et al. (13) reported that both enzymes had normal activity in fibroblasts cultured in biotin-supplemented medium ( $24 \mu \mathrm{g} / \mathrm{liter})$ but little or no activity when the biotin content was reduced by a factor of 10 . The authors postulated a defect of the holocarboxylase synthetase, the enzyme required to bind the biotin cofactor to apocarboxylase. Recently, Roth et al. reported a patient who presented with $\beta$-methylcrotonic aciduria associated with lacticacidosis (10). This patient also responded clinically to biotin administration, but succumbed to complications of cyanotic congenital heart disease.

In this study, we have characterized additional mutant strains to confirm the nature of the complementation map and to determine if a new complementation group, defined by the biotin-responsive disorder described above, exists. In addition, we have demonstrated a deficiency of yet another enzyme activity, that of pyruvate carboxylase, in fibroblasts of biotinresponsive patients grown under biotin-free conditions.

\section{METHODS}

Source and growth of cells. All strains were subcultures of skin fibroblasts derived from patients with propionicacidemia or biotin-responsive organicaciduria. The clinical histories of the biotin-responsive patients have been reported $(8,10)$. Strains previously mapped to complementation groups have been described (7). Several of the strains were kindly provided by Dr. L. E. Rosenberg and Dr. Y. E. Hsia, New Haven, Connecticut. Others were provided through the cell bank at the University of California, San Diego. Three normal strains were included as controls. Fibroblast monolayers were routinely grown in alpha medium ( $\alpha$-minimal essential medium [ $\alpha$-MEM] [14] supplemented with $15 \%$ fetal calf serum [FCS], Flow Laboratories, Inc., Mississauga, Ontario)) without antibiotics at $37^{\circ} \mathrm{C}$ in $5 \% \mathrm{CO}_{2} / 95 \%$ air atmosphere. All strains were examined for evidence of mycoplasma contamination by broth or agar assay or examination of uridine diphosphate-phosphorylase activity, after two passages in antibiotic-free medium. ${ }^{2}$ No evidence of mycoplasma contamination was found in any of the strains used in this study.

Biotin starvation. Alpha medium contains $0.1 \mathrm{mg} / \mathrm{liter}$ biotin, $\cong 3 \mu \mathrm{g} /$ liter of which is contributed by $15 \%$ FCS (13). Biotin-free medium was prepared by combining $\alpha$-MEM lacking biotin, FCS to $15 \%$ (vol/vol), and $30 \mathrm{U} / \mathrm{liter}$ avidin (Sigma Chemical Co., St. Louis, Mo.). 100 U/liter penicillin

${ }^{2}$ Microplasma testing was done by P. Quinn at the Hospital for Sick Children, Toronto. and $100 \mu \mathrm{g} /$ liter streptomycin were included in the medium. The biotin contributed by the FCS was effectively removed by the addition of the 10-fold excess of avidin (15).

Complementation tests. Complementation tests involving the 16 new mutant strains were done by autoradiographic analysis after $\left[{ }^{14} \mathrm{C}\right]$ propionate incorporation, as described (7). Cells were fused in the presence of $50 \%$ polyethylene glycol 1,000 ( $\alpha$-hydro- $\omega$-hydroxy-poly (oxy-1,2-ethaneidyl)1000; J. T. Baker Chemical Co., Phillipsburg, N. J.) or inactivated Sendai virus (Connaught Laboratory, Toronto, Ontario). New strains were assigned to complementation groups on the basis of a comparison between $\left[{ }^{14} \mathrm{C}\right]$ propionate incorporation in selffusion and test fusions with members of the known pcc groups. Strains used in the complementation tests with biotin-responsive strains 456 and 541 were maintained in biotin-free medium for at least $2 \mathrm{wk}$ before fusing.

Enzyme assays. The enzyme activity of cultures grown in biotin-free or biotin-supplemented conditions was determined on cells from confluent cultures of T-75 flasks (Falcon Labware, Div. of Becton, Dickinson \& Co., Oxnard, Calif.) grown in the appropriate medium for at least two to three subcultures. Cell extracts were prepared by harvesting confluent monolayers $\left(10^{6}-10^{7}\right.$ cells $)$ by dissociation with $0.25 \%$ trypsin (0.134 M trisodiumcitrate and $0.015 \mathrm{M} \mathrm{KCl}, \mathrm{pH} 7.8$ ). Cells were collected in $15-20 \mathrm{ml}$ of the appropriate medium and centrifuged at $800 \mathrm{~g}$ for $10 \mathrm{~min}$. The pellets were washed once with $15 \mathrm{ml}$ and once with $1 \mathrm{ml}$ cold phosphate-buffered saline and centrifuged at $2,000 \mathrm{rpm}$ for $10 \mathrm{~min}$ after each washing. The pellets were resuspended in $50 \mu \mathrm{l}$ of $1 \mathrm{mM}$ dithiothreitol $/ 10^{6}-10^{7}$ cells. The cell suspensions were sonicated on ice with a 10-s burst at setting 20 on an Artek biodismembrator (Fisher Scientific Co., Pittsburgh, Pa.).

Propionyl-CoA carboxylase, $\beta$-methylcrotonyl-CoA carboxylase, and pyruvate carboxylase were assayed by determining the enzyme-dependent incorporation of $\left[{ }^{14} \mathrm{C}\right]$ bicarbonate into acid-nonvolatile form. All three enzyme assays were linear for $0-20 \mathrm{~min}$ and from $0-70 \mu \mathrm{g}$ protein per assay tube. The PCC assay was modified from our previous procedure (7) by the addition of $0.1 \%$ Triton X-100 (Rohm and Haas Co., Philadelphia, Pa.) (Table I). The assay volume was reduced to $0.05 \mathrm{ml}$.

The MCC assay (Table I) was modified from the method of Weyler et al. (13). The assay mix contained in a vol of $0.05 \mathrm{ml}$ : $60 \mathrm{mM}$ Tris- $\mathrm{HCl} \mathrm{pH} 8.2,10 \mathrm{mM}$ reduced glutathione, $10 \mathrm{mM}$ $\mathrm{MgCl}_{2}, 2 \mathrm{mM}$ neutralized ATP, $0.1 \%$ Triton X-100, $50 \mathrm{mM}$ $\mathrm{KCl}, 0.5 \mathrm{mM}$ EDTA, $3 \mathrm{mM} \beta$-methylcrotonyl-CoA (P-L Biochemicals, Inc., Milwaukee, Wis.) and $10 \mathrm{mM}\left[{ }^{14} \mathrm{C}\right] \mathrm{NaHCO}_{3}$ $(12.2 \mathrm{mCi} / \mathrm{mmol}$; New England Nuclear, Boston, Mass.). Blank tubes were prepared by omitting the $\beta$-methylcrotonyl-CoA.

The PC assay (Table I) was modified from the method of Utter et al. (16) as described for tissue samples. The assay mix contained in $0.05 \mathrm{ml}: 100 \mathrm{mM}$ Tris- $\mathrm{HCl}$ pH $7.8,0.5 \%$ Triton X-100, $5 \mathrm{mM} \mathrm{MgCl}_{2}, 2.5 \mathrm{mM}$ neutralized ATP, 0.33 $\mathrm{mM}$ acetyl-CoA (Sigma Chemical Co.). $0.004 \mathrm{mg}$ citrate synthase condensing enzyme (Boehringer Mannheim, Biochemicals, Indianapolis, Ind.) $50 \mathrm{mM} \mathrm{KCl}, 5 \mathrm{mM}$ sodium pyruvate (fresh) and $10 \mathrm{mM}\left[{ }^{14} \mathrm{C}\right] \mathrm{NaHCO}_{3}(12.2 \mathrm{mCi} / \mathrm{mmol})$. Blanks were prepared by omitting the pyruvate. Citrate synthase was included to convert acid-volatile $\left[{ }^{14} \mathrm{C}\right]$ oxaloacetate into acid-involatile $\left[{ }^{14} \mathrm{C}\right]$ citrate; however, later experiments showed that the addition of exogenous enzyme was not necessary for crude extracts.

For all assays, $5 \mu \mathrm{l}$ cell sonicate were combined with the assay mix in plastic microfuge tubes (Beckman Instruments, Inc., Fullerton, Calif. capacity $150 \mu \mathrm{l}$ ) and the reaction was initiated with the addition of $\left[{ }^{14} \mathrm{C}\right]$ bicarbonate. All assays were done in duplicate. Incubation was carried out at $37^{\circ} \mathrm{C}$ for $20 \mathrm{~min}$ for all three enzyme assays. The reactions were stop- 
TABLE I

Requirements of $\beta$-Methylcrotonyl-CoA, Pyruvate, and Propionyl-CoA Carboxylase Assay Systems*

\begin{tabular}{|c|c|c|c|c|c|}
\hline $\begin{array}{c}\beta \text {-Methylcrotonyl-CoA } \\
\text { carboxylase }\end{array}$ & $\begin{array}{l}\text { Specific } \\
\text { activity }\end{array}$ & Pyruvate carboxylase & $\begin{array}{l}\text { Specific } \\
\text { activity }\end{array}$ & $\begin{array}{l}\text { Propionyl-CoA } \\
\text { carboxylase }\end{array}$ & $\begin{array}{l}\text { Specific } \\
\text { activity }\end{array}$ \\
\hline & $\begin{array}{l}\text { nmol/min/mg } \\
\text { protein }\end{array}$ & & $\underset{\text { protein }}{\text { nmol } / \mathrm{min} / \mathrm{mg}}$ & & $\begin{array}{c}\text { nmol/min } / m g \\
\text { protein }\end{array}$ \\
\hline Complete & 0.54 & Complete & 0.31 & Complete & 0.65 \\
\hline ATP omitted & 0.02 & ATP omitted & 0.02 & ATP omitted & 0.06 \\
\hline $\mathrm{MgCl}_{2}$ omitted & 0.01 & $\mathrm{MgCl}_{2}$ omitted & 0.01 & $\mathrm{MgCl}_{2}$ omitted & 0.01 \\
\hline $\mathrm{KCl}$ omitted & 0.14 & $\mathrm{KCl}$ omitted & 0.12 & $\mathrm{KCl}$ omitted & 0.09 \\
\hline Triton X-100 omitted & 0.36 & Triton X-100 omitted & 0.25 & Triton X-100 omitted & 0.35 \\
\hline Glutathione omitted $\ddagger$ & 0.53 & Acetyl-CoA omitted & 0.03 & Glutathione omitted & 0.61 \\
\hline $\begin{array}{l}\text { EDTA omitted } \\
B \text {-methylcrotonyl-CoA }\end{array}$ & 0.45 & Pyruvate omitted & 0.02 & Propionyl-CoA omitted & 0.01 \\
\hline omitted & 0.01 & & & & \\
\hline
\end{tabular}

* Assay tubes were incubated at $37^{\circ} \mathrm{C}$ for $20 \mathrm{~min}$. The complete assay systems are described in the text.

‡ Glutathione was routinely added to the PCC and MCC assay mixes, but was found to be unnecessary in extracts prepared in $10^{-3}$ DTT.

ped with the addition of $50 \mu \mathrm{l} 1.0 \mathrm{~N}$ perchloric acid in a fume exhaust hood to evolve unreacted $\left[{ }^{14} \mathrm{C}\right]$ bicarbonate as ${ }^{14} \mathrm{CO}_{2}$. The tubes were centrifuged at $800 \mathrm{~g}$ for $3 \mathrm{~min}$ and $50 \mu \mathrm{l}$ of the supernatant was transferred to a scintillation vial. The contents of the vials were evaporated to dryness overnight without heat to remove any remaining ${ }^{14} \mathrm{CO}_{2}$. The dried residue was resuspended in $1 \mathrm{ml} \mathrm{H}_{2} \mathrm{O}$, and $10 \mathrm{ml}$ Aquasol scintillation fluid (American Cyanamid Co., Bound Brook, N. J.) was added for counting in a liquid scintillation counter (model L5-250, Beckman Instruments Inc.). Specific activity was defined as the amount of enzyme required to convert $1 \mathrm{nmol}$ of $\left[{ }^{14} \mathrm{C}\right]-$ bicarbonate to acid-nonvolatile form in $1 \mathrm{~min}$. Protein was determined by the method of Lowry et al. (17).

\section{RESULTS}

Complementation analysis. 14 new biotin-nonresponsive mutant strains with PCC deficiency were examined for complementation with "tester" strains from the established complementation groups (7). The results of these tests are shown in the complementation map in Fig. 1. Six new strains were found to complement tester strains from all groups except $p c c A$. This defines these mutants as members of the $p c c A$ group. Similarily, three new mutants were assigned to $p c c B$ and one to $p c c C$. Three new strains complemented the tester strains from $p c c A$, but failed to complement strains from either the $p c c B$ or $p c c C$ groups. This classifies these mutants into the $p c c B C$ group.

For the complementation analysis of the biotin-responsive strains, we took advantage of the deficiency of PCC activity that occurred in cells grown in biotinfree medium; however, this also required that the PCC tester strains be starved for biotin. To determine if such starvation was in fact effective, we examined $\left[{ }^{14} \mathrm{C}\right]-$ propionate incorporation, using the previously described autoradiographic procedure in cells of strains 456 (bio), 541 (bio), 447 (pccA), 500 (pccBC), and 595 (normal) after growth in biotin-supplemented or biotinfree medium (Fig. 2). Normal cells from both biotinfree (Fig. 2a) and biotin-supplemented (Fig. 2d) cultures were completely covered with silver grains, showing that PCC activity was not appreciably affected by biotin starvation. Neither the pccA mutant, strain 447 (Fig. 2b and e), nor the pccBC mutant, strain 500, was able to incorporate the label after growth in either medium. These mutants are unable to metabolize propionate because of their genetic defect, and they are not sensitive to exogenous biotin concentration. The biotin-responsive strains 456 (Fig. 2f) and 541 showed silver grain patterns indistinguisable from those of normal cells after growth in biotin-supplemented medium. However, the density of the silver grain patterns was reduced to background in both cases (Fig.

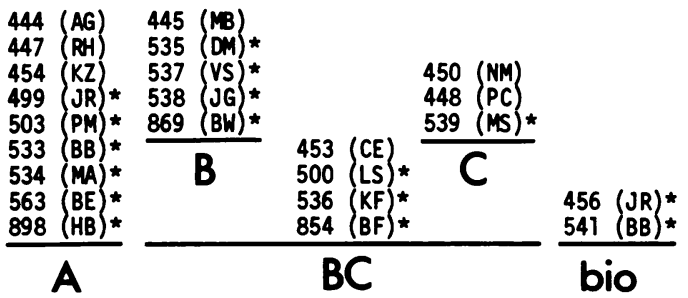

FIGURE 1 Complementation map of mutants deficient in propionyl-CoA carboxylase activity. Each strain is designated by its number and the patient's initials. Letters refer to pcc groups. The map is read as following (7). Mutant strains placed within a group fail to complement each other and are placed over a solid line to define that group. Strains placed in different groups over nonoverlapping lines. (e.g., pccA vs. pccB, $p c c B$ vs. $p c c C$ ) complement each other, while strains placed in different groups over overlapping lines fail to complement each other (e.g., $p c c B$ or $p c c C$ vs. $p c c B C)$. Note that mutant strains in the same group behave identically in complementation tests. ${ }^{*}$, strains mapped in this study 


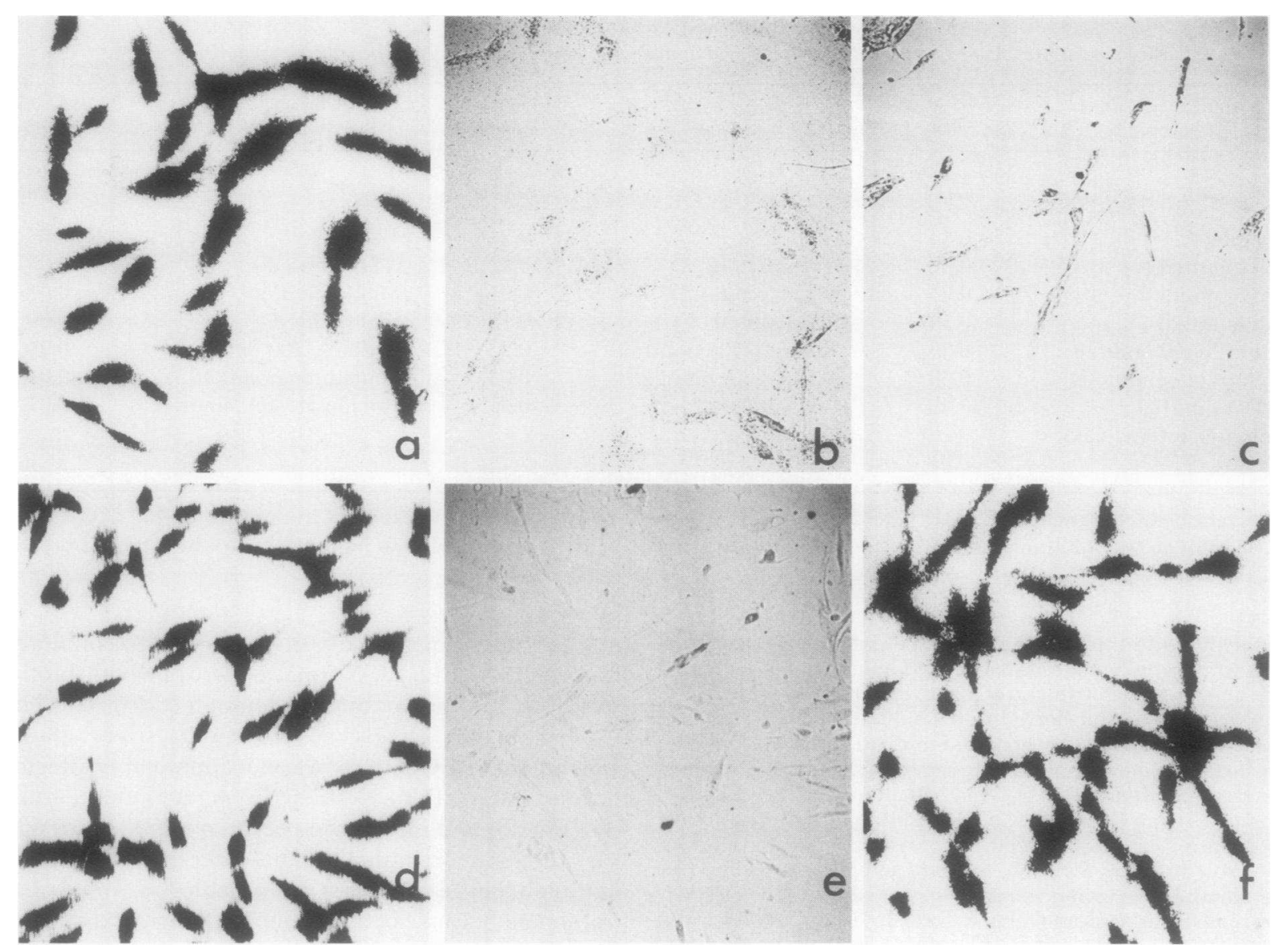

FIGURE 2 Silver grain patterns obtained after autoradiography of fibroblasts incubated in the presence of $\left[{ }^{14} \mathrm{C}\right]$ propionate after culture in either biotin-free (-biotin) or biotin-supplemented (+biotin) medium. The presence of a dense cover of silver grains over cells corresponds to functional propionyl-CoA carboxylase. (a) normal cells, - biotin; (b) pccA mutant, - biotin; (c) bio mutant, -biotin; (d) normal cells, +biotin; (e) pccA mutant, +biotin; (f) bio mutant, + biotin.

2c, strain 456) after growth in biotin-free medium for $2 \mathrm{wk}$ before transfer to the isotope medium.

The above results showed that complementation could be examined in biotin-responsive strains. They were fused with each other and with tester strains from each of the previously defined pcc complementation groups after growth in biotin-free medium. Negative controls were generated by self-fusion. Fig. 3 shows the silver grain patterns obtained for fusions involving strain 456. Fusions with either a pccA (Fig. 3a) or a pccBC (Fig. 3b) mutant showed heavy silver grain density over multinucleate cells, indicative of complementation between these strains. This contrasts with the very few silver grains observed over multinucleate cells of the self-fusion 456/456 (Fig. 3c). Similar results were observed for fusions between strain 456 and $p c c C$ mutants, so that strain 465 was shown to complement members of all the pcc groups. The same pattern of results was obtained for fusions between strain 541 and the various pcc mutants.
The result of fusion of strain 456 with strain 541 (Fig. $3 d$ ) was indistinguishable from that found in either selffusion in that no increase in silver grain intensity was observed over multinucleate cells. Thus, the biotinresponsive strains failed to complement each other in heterokaryons, but consistently complemented members of every other group. This establishes a new complementation group called bio. The results of these fusions are summarized in Table II.

Carboxylase activities. Weyler et al. (13) have suggested that strain 456 lacks holocarboxylase synthetase activity. Therefore, we decided to extend the examination of carboxylase activities in the bio mutants to include pyruvic carboxylase, since this enzyme is also expressed in cultured fibroblasts $(18,19)$.

The specific activities of PCC, MCC, and PC were examined in fibroblast extracts of mutant and normal strains after prolonged cultured in biotin-supplemented and biotin-free media. As shown in Table III, normal fibroblasts showed levels of all three enzyme 


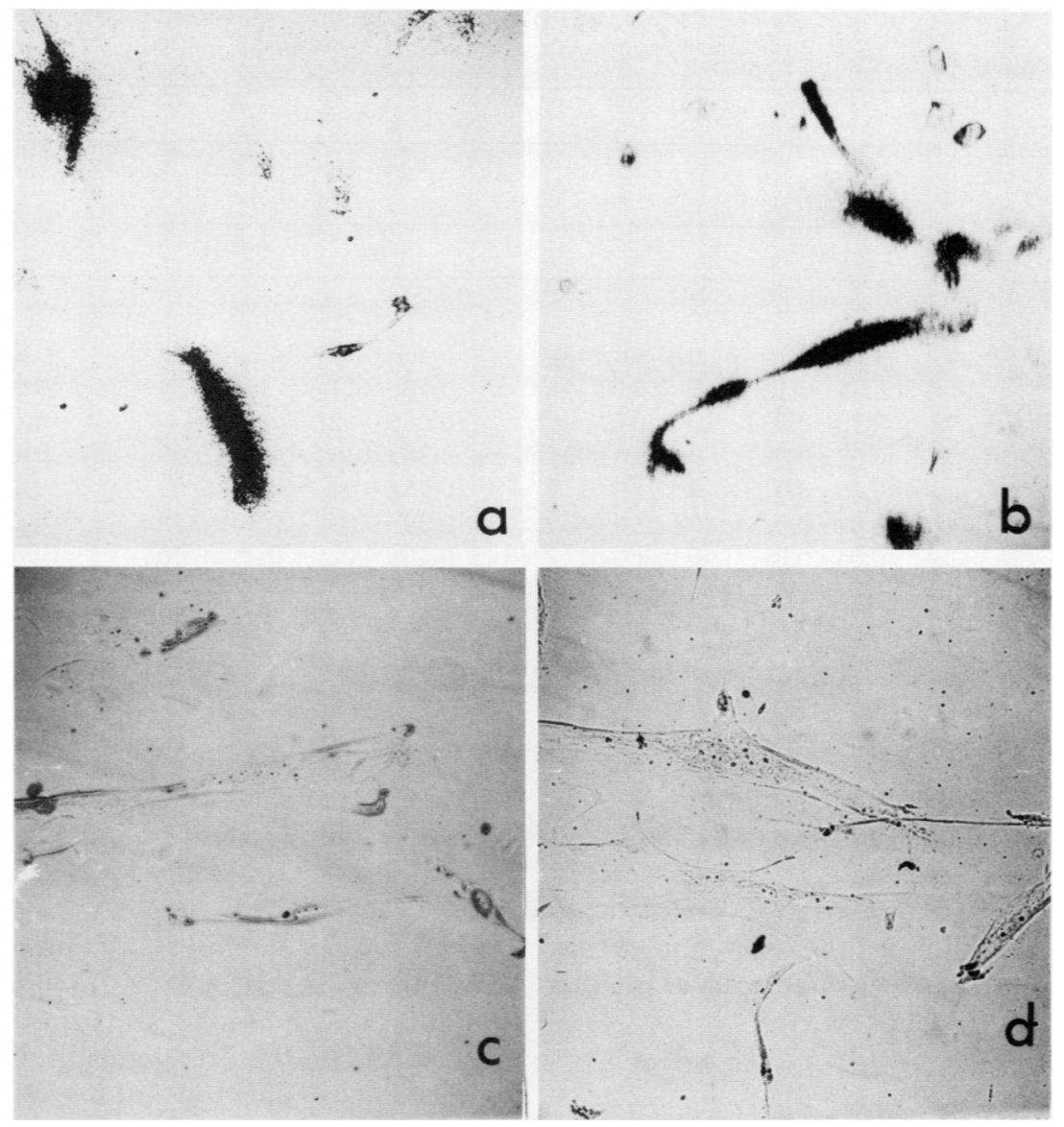

FIGURE 3 Results of representative complementation tests with bio mutants. The cells in each frame were produced by fusion of strain 456 (bio) with different tester pcc mutants in pairwise combinations. The intensity of the silver grain pattern observed over multinucleate cells by autoradiography following incubation with $\left[{ }^{14} \mathrm{C}\right]$ propionate is taken as a measure of complementation. Fusions in each frame are: (a) 456/pccA; (b) 456/pccBC; (c) 456/456; (d) 456/541. Strain 541 is a bio mutant.

activities that were not significantly affected by growth in biotin-free medium for as long as $8 \mathrm{wk}$. The average specific activities of the carboxylases in biotin-free medium were always within the normal ranges obtained for cells grown in biotin-supplemented medium. The carboxylase activities of four pcc mutants, strain 447 $(p c c A)$, strain $445(p p c B)$, strain $451(p c c C)$, and strain

TABLE II

Complementation Results between bio and pcc Tester Strains*

\begin{tabular}{lcccccc}
\hline & 456 & 541 & $p c c A$ & $p c c B$ & $p c c C$ & $p c c B C$ \\
\hline bio 456 & 0 & 0 & + & NDł & + & + \\
bio 541 & & 0 & + & + & + & + \\
\hline
\end{tabular}

* Tester strains were: $p c c A, 447,499,503 ; p c c B, 445 ; p c c C$, 451, 539; pccBC, 500, 536.

$\ddagger N D$, not determined. $500(p c c B C)$ were also examined after growth in biotinfree or biotin-supplemented medium (Table III). All four strains showed $<5 \%$ of control PCC activity after growth in either medium, whereas MCC and PC activities were normal. These $p c c$ mutants are therefore only deficient in PCC activity and the defect is unresponsive to biotin supplementation.

In contrast, the bio mutant strains 456 and 541 displayed a multiple carboxylase defect that depended on biotin depletion for its expression. The PCC and MCC activities of the bio strains were within the low normal range under routine culture conditions in biotin-supplemented medium (Table III). Interestingly, the PC activities were well above the normal range established for strain $\mathbf{5 9 5}$ and the various $p c c$ strains. Transfer of bio cells to biotin-free medium produced a dramatic decrease in the activities of all three enzymes from normal to background levels. Most of the reduction in specific activities occurred within $8 \mathrm{~d}$ of transfer, the 
TABLE III

Enzyme Activities after growth in Biotin-supplemented or Biotin-deficient Medium

\begin{tabular}{|c|c|c|c|c|c|c|c|}
\hline \multirow[b]{3}{*}{ Strain } & \multirow{3}{*}{$\begin{array}{c}\text { Complementation } \\
\text { group }\end{array}$} & \multicolumn{6}{|c|}{ Specific activity* } \\
\hline & & \multicolumn{2}{|c|}{ Propionyl-CoA carboxylase } & \multicolumn{2}{|c|}{$\begin{array}{c}\beta \text {-Methylcrotonyl-CoA } \\
\text { carboxylase }\end{array}$} & \multicolumn{2}{|c|}{ Pyruvate carboxylase } \\
\hline & & + biotin & -biotin & +biotin & -biotın & +biotin & - biotin \\
\hline & & \multicolumn{6}{|c|}{ nmolimin/mg protein } \\
\hline 595 & $+\ddagger$ & $1.00 \pm 0.19$ & $0.95 \pm 0.14$ & $0.40 \pm 0.11$ & $0.36 \pm 0.04$ & $0.28 \pm 0.09$ & $0.24 \pm 0.09$ \\
\hline 541 & bio & $0.81 \pm 0.11$ & $<0.01$ & $0.40 \pm 0.11$ & $<0.01$ & $0.90 \pm 0.44$ & $<0.05$ \\
\hline 456 & bio & $0.79 \pm 0.06$ & $<0.01$ & $0.28 \pm 0.02$ & $<0.01$ & $1.18 \pm 0.33$ & $<0.05$ \\
\hline 500 & $p c c B C$ & $0.02 \pm 0.001$ & $0.02 \pm 0.002$ & $0.38 \pm 0.10$ & $0.35 \pm 0.05$ & $0.41 \pm 0.20$ & $0.32 \pm 0.06$ \\
\hline 445 & $p c c B$ & $0.03 \pm 0.01$ & $0.03 \pm 0.01$ & $0.48 \pm 0.01$ & $0.39 \pm 0.03$ & $0.24 \pm 0.07$ & $0.20 \pm 0.06$ \\
\hline 447 & pccA & $0.01 \pm 0.0$ & $0.01 \pm 0.002$ & $0.39 \pm 0.05$ & $0.30 \pm 0.12$ & $0.25 \pm 0.08$ & $0.28 \pm 0.12$ \\
\hline 451 & $p c c C$ & $0.04 \pm 0.01$ & $0.02 \pm 0.01$ & $0.48 \pm 0.02$ & $0.38 \pm 0.06$ & $0.34 \pm 0.09$ & $0.35 \pm 0.04$ \\
\hline
\end{tabular}

* Results are \pm SD. $n=5-10$ for experiments involving strains 541 and $595 ; n=2-4$ for strain 456 ; and $n=2$ for all other experiments.

$\ddagger+$, normal strain.

time required for a $1: 4$ subculture of the mutant cells (T-75 flask) to reach confluence. By the end of a second subculture of these cells, no PCC, MCC, or PC activity over background was detectable. After transfer back to biotin-supplemented medium, full restoration of carboxylase activities in bio cells was achieved within one subculture.

\section{DISCUSSION}

To investigate the genetic basis of clinical heterogeneity in propionicacidemia, we previously examined complementation between PCC-deficient mutant fibroblast strains. Our results revealed two major complementation groups, designated $p c c A$ and $p c c B C$ and confirmed the recessive expression of PCC deficiency in heterokaryons (7). Clinical heterogeneity was not correlated with genetic heterogeneity, since two patients, one with a lethal disorder and the other with a very mild expression, were assigned to the same complementation group $(p c c C)$. With the addition of the new mutants in this study, our results have been extended considerably, with the following conclusions. We have confirmed that $p c c B C$ is a complex group consisting of two subgroups, $p c c B$ and $p c c C$. Mutant strains in $p c c B$ complement strains in $p c c C$, but fail to correct the defect in $p c c B C$ strains. This is a pattern that would be expected for intragenic complementation within a $p c c B C$ gene. If so, it is surprising that there would be so many such mutants, since intragenic complementation would be expected to occur as a rare event. The number of $p c c B C$ mutants would have been expected to predominate. It implies that the mutant gene product, possibly a polypeptide of PCC or holocarboxylase synthetase, has two centers of function such that a de- fect in one does not inactivate the other. Such an explanation for intragenic complementation has been presented before, notably for $\beta$-galactosidase of $E s c h$ erichia coli (20).

If all the $p c c$ complementation groups represented the same gene, then a class of mutants called pccABC should have been found. In fact, this would have been expected to be the predominant class, since all of the other complementation groups would have resulted from the "rare" case of intragenic complementation. Thus, with the mapping of some 23 pcc mutants, the absence of the $p c c A B C$ class strongly suggests that $p c c A$ and $p c c B C$ represent two separate genes, perhaps encoding different subunits of PCC (21-23).

We have shown that three carboxylases, PCC, MCC, and $\mathrm{PC}$, were deficient in fibroblast extracts of two patients who responded clinically to biotin administration. Fibroblasts of these two patients failed to complement each other in heterokaryons, but did complement members of every other $p c c$ group. This establishes a new complementation group, bio, in PCC deficiency. The complementation results also show that the bio mutation must be expressed recessively, since a dominant mutation would have failed to complement the known $p c c$ groups. Although our studies show that these patients have allelic mutations, they showed differences clinically. J.R. (strain 456) was studied at 5 mo of age with metabolic acidosis and ketosis and a severe erythematous rash (8). B.B. (strain 541) presented, immediately after birth, the metabolic acidosis, ketosis, and lactic acidemia progressing to seizures and death in $5 \mathrm{~d}(10)$.

Both patients had an organicaciduria, which could have predicted all three carboxylase defects. They both excreted abnormal amounts of $\beta$-methylcrotonate and 
$\beta$-hydroxyisovalerate and J.R. also excreted $\beta$-methylcrotonylglycine $(10,24,25)$. These findings are consistent with the deficiency of MCC activity. In addition both patients excreted $\beta$-hydroxypropionate and J.R. also excreted propionate, methylcitrate, and tiglylglycine, findings consistent with the PCC defect. Finally, both patients excreted large amounts of lactate and a lacticacidosis was also demonstrated in BB. These findings correlate with a deficiency of PC activity. These results emphasize the importance of screening urinary organic acids in the differential diagnosis of this multiple carboxylase disorder during the neonatal period.

The bio mutants can be distinguished biochemically from normal cells and members of the other PCCdeficient complementation groups by the dramatic change in their carboxylase activities on transfer to biotin-free conditions. Even after $8 \mathrm{wk}$ culture in biotin-free medium, normal fibroblasts retained at least $90 \%$ of their initial carboxylase activities (Table III). In contrast, under the latter conditions, strain 456 showed no detectable carboxylase activities. Strain 541 , which does not complement strain 456, exhibited similar carboxylase deficiencies. All three enzyme activities returned to normal levels when the cells of both strains were subcultured into biotin supplemented medium. These results reflect the biotin responsiveness of at least one of the patients. All of the symptoms of J.R. resolved rapidly upon the oral administration of $10 \mathrm{mg}$ biotin/d, and he remains clinically well while receiving $0.5 \mathrm{mg} / \mathrm{d}(26)$. In B.B. there was some improvement of the metabolic acidosis on intravenous administration of $0.2 \mathrm{mg}$ of biotin, but death occurred the following day (10).

A pleiotropic deficiency of three carboxylases such as that found in the bio mutants could be accounted for by a defect either in biotin transport at the cellular or mitochondrial level, or in the holocarboxylase synthetase. It is unlikely that there are separate primary defects in each of the PCC, MCC, and PC enzyme proteins. A defect in cellular biotin transport has been tentatively ruled out from experiments with cell-free extracts. ${ }^{3}$ These experiments suggest that functional apocarboxylase does occur in fibroblasts of strain 456 which can be converted to active holoenzyme by factors in a normal cell extract but not by the addition of biotin and ATP alone. Thus, a defect of biotin transport is not likely to be the site of the mutation. The results could be explained if the bio mutants had a defect of the holocarboxylase synthetase. PCC, MCC, and PC are mitochondrial enzymes, and conceivably one synthetase could recognize and attach biotin to all three apocarboxylases. Achuta-Murthy and Mistry (27) have identified separate cytosolic and mitochrondrial holo-

\footnotetext{
${ }^{3}$ L. Sweetman. Unpublished data.
}

carboxylase synthetases in chicken liver extracts. Therefore, it would be interesting to determine if acetyl-CoA carboxylase, a cytosolic enzyme, is defective in the bio mutants.

\section{ACKNOWLEDGMENT}

These studies were supported by grant MA-5698 from The Medical Research Council of Canada.

\section{REFERENCES}

1. Rosenberg, L. E. 1978. Disorders of propionate, methylmalonate, and cabalamin metabolism. In The Metabolic Basis of Inherited Disease. J. B. Stanbury, J. B. Wyngaarden, D. S. Fredrickson, editors. McGraw-Hill Book Company, New York. 411-429.

2. Tanaka, K. 1975. Disorders of organic acid metabolism. In Biology of Brain Dysfunction, G. E. Gaull, editor. Plenum Publishing Corp., New York. Volume 3. 415-517.

3. Mahoney, M. J., Y. E. Hsia, and L. E. Rosenberg. 1971. Propionyl-CoA carboxylase deficiency (propionicacidemia): a cause of non-ketotic hyperglycinemia. Pediatr. Res. 5: 395.

4. Wadlington, W. B., A. Kilroy, T. Ando, L. Sweetman, and W. L. Nyhan. 1975. Hyperglycinemia and propionyl-CoA carboxylase deficiency and episodic severe illness without consistent ketosis. J. Pediatr. 86: 707-712.

5. Guibaud, P., P. Divry, G. Marcon, J. B. Cotton, C. Collombel, and F. Larbue. 1975. Une forme a revelation tardive de l'acidemie propionique. Arch. Fr. Pediatr. 32: 259-274.

6. Paulsen, E. P., and Y. E. Hsia. 1974. Asymptomatic propionicacidemia: variability of clinical expression in a Mennonite kindred Am. J. Hum. Genet. 26: 66a. (Abstr.)

7. Gravel, R. A., K. F. Lam, K. J. Scully, and Y. E. Hsia. 1977. Genetic complementation of propionyl-CoA carboxylase deficiency in cultured human fibroblasts. Am. J. Hum. Genet. 29: 378-388.

8. Gompertz, D., G. H. Draffan, J. L. Watts, and D., Hull. 1971. Biotin-responsive $\beta$-methylcrotonyl-glycinuria. Lancet. II: 22.

9. Gompertz, D., K. Bartlett, D. Blair, and M. M. Stern. 1973. Child with a defect in leucine metabolism associated with $\beta$-hydroxyisovaleric aciduria and $\beta$-methylcrotonylglycinuria. Arch. Dis. Child. 48: 975-977.

10. Roth, K., R. Cohn, J. Yandrasitz, G. Preti, P. Dodd, and S. Segal. 1976. Beta-methylcrontonic aciduria associated with lactic acidosis. J. Pediatr. 88: 229-235.

11. Hillman, R. E., J. P. Keating, and J. C. Williams. 1978. Biotin-responsive propionic acidemia presenting as the rumination syndrome. J. Pediatr. 92: 439-441.

12. Bartlett, K. and D. Gompertz. 1976. Combined carboxylase defect: biotin-responsiveness in cultured fibroblasts Lancet. II: 804-805.

13. Weyler, W., L. Sweetman, D. C. Maggio, and W. L. Nyhan. 1977. Deficiency of propionyl-CoA carboxylase and methylcrotonyl-CoA carboxylase in a patient with methylcrontonylglycinuria. Clin. Chim. Acta. 76: 321-328.

14. Stanners, C. P., G. L. Eliceiri, and H. Green. 1971. Two types or ribosomes in mouse-hamster hydrid cells. Nat. New Biol. 230: 52-54.

15. Green, N. M. 1963. The use of ${ }^{14} \mathrm{C}$-biotin for kinetic studies and for assay. Biochem. J. 89: 585-591.

16. Utter, M. F., and D. B. Keech. 1963. Pyruvate carboxylase. I. Nature of the reaction. J. Biol. Chem. 283: 2603-2608.

17. Lowry, O. H., N. J. Rosenbrough, A. L. Farr, and R. J. 
Randall. 1951. Protein measurement with the Folin phenol reagent. J. Biol. Chem. 193: 265-275.

18. Raghunathan, R., J. D. Russell, and I. J. Arinze. 1977. Pyruvate carboxylase and phosphoenolpyruvate carboxylase in cultured human fibroblasts. J. Cell. Physiol. 92: 285-292.

19. Atkin, B. M., M. F. Utter, and M. B. Weinberg. 1979. Pyruvate carboxylase and phosphoenolpyruvate carboxykinase activity in leukocytes and fibroblasts from a patient with pyruvate carboxylase deficiency. Pediat. Res. 13: $38-43$.

20. Zabin, I., and M. R. Villarejo. 1975. Protein complementation. Ann. Rev. Biochem. 44: 295-313.

21. Lau, E. P., B. C. Cochran, L. Musson, and R. R. Fall. 1979. Bovine kidney 3-methyl-crontonyl-CoA and propionylCoA carboxylase: each enzyme contains non-identical subunits. Proc. Natl. Acad Sci. U. S. A. 76: 214-218.

22. Wolf, B., Y. E. Hsia, and L. E. Rosenberg. 1978. Biochemical differences between mutant propionyl-CoA carboxylase from two complementation groups. Am. J. Hum. Genet. 30: 455-464.

23. Wolf, B., and L. E. Rosenberg. 1978. Heterozygote ex- pression in propionyl-coenzyme A carboxylase deficiency: differences between major complementation groups. $J$. Clin. Invest. 62: 931-936.

24. Chalmers, R. A., S. Bickle, and R. W. E. Watts. 1974. A method for the determination of volatile organic acids in aqueous solutions and urine, and the results obtained in propionic acidaemia, $\beta$-methylcrotonylglycinuria and methylmalonic acidaemia. Clin. Chim. Acta. 52: 31-41.

25. Chalmers, R. A., A. M. Lawson, A. M., and R. W. E. Watts. 1974. Studies on the urinary acidic metabolites excreted by patients with $\beta$-methylcrotonylglycinuria, propionic acidaemia and methylmalonic acidaemia, using gas-liquid chromatography and mass spectrometry. Clin. Chim. Acta. 52: 43-51.

26. Sweetman, L., S. P. Bates, D. Hull, and W. L. Nyhan. 1977. Propionyl-CoA carboxylase deficiency in a patient with biotin-responsive 3-methylcrotonylglycinuria. Pediatr. Res. 11: 1144-1147.

27. Achuta-Murthy, P. N., and S. P. Mistry. 1974. Some aspects of biotin binding to protein catalyzed by biotindeficient chicken liver preparations. Proc. Soc. Exp. Biol. Med. 145: 565-570. 